\title{
Closure of a rectal perforation by clipping the margins to presacral tissue
}
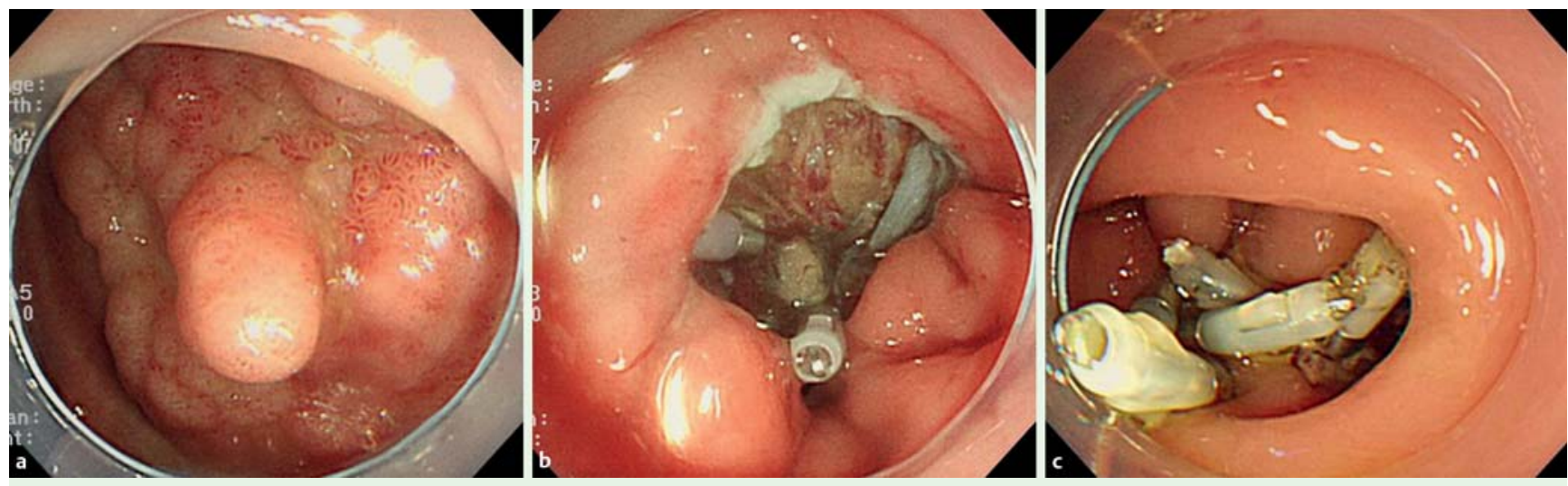

Fig. 1 a A flat, 30-mm-wide rectal adenoma underwent endoscopic mucosal resection. b An approximately 25-mm-wide perforation was noted at the mucosectomy site, and the marginal mucosa of the perforation was circumferentially attached to the tissue adjacent to the rectum using endoclips. c Closure of the perforation was confirmed 10 days later.

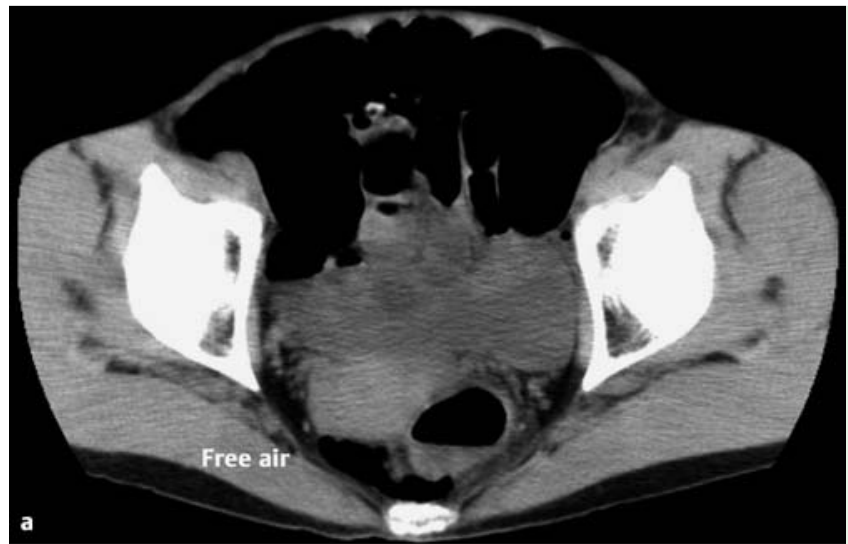

Fig. 2 a CT scan of the abdomen after endoscopic mucosal resection revealed free air in the presacral space, but no pneumoperitoneum. $\mathbf{b}$ The amount of free air had not increased on the next day.

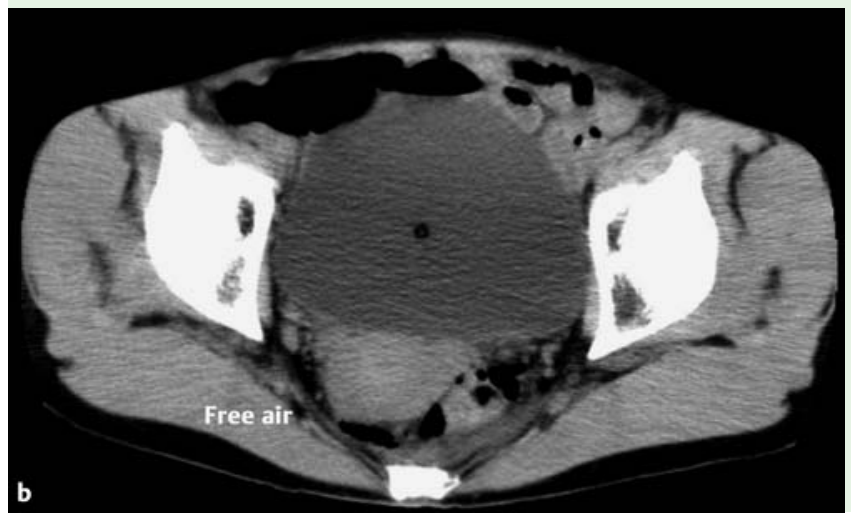

Iatrogenic colorectal perforation during therapeutic colonoscopy is a rare but serious complication [1]. It is usually managed with immediate open surgery. However, conservative therapy has recently been advocated [2], provided that adequate precolonoscopic bowel preparation has been carried out and that no peritoneal signs are present [3]. Asymptomatic per- forations after colonoscopic polypectomy have been conservatively managed using close observation, even in the presence of intra-abdominal free air [4]. Recently, endoclip closure was used to treat iatrogenic colonic perforation conservatively [5]; however, endoclipping cannot be used to repair perforations that are larger than the endoclip (diameter $11 \mathrm{~mm}$ ) [5].

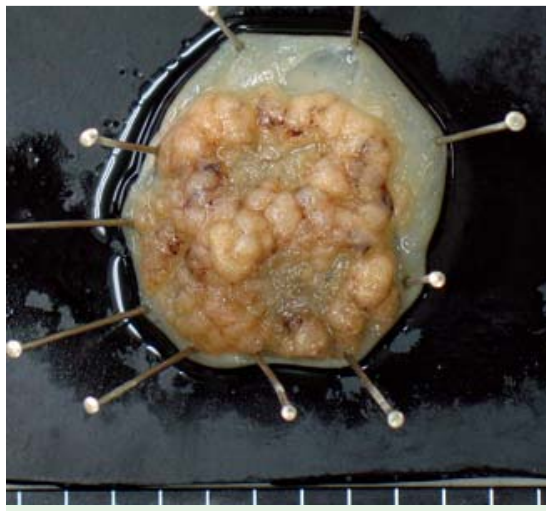

Fig. 3 The resected specimen was $38 \mathrm{~mm}$ wide, and the pathological diagnosis was tubulovillous adenoma.

We report the case of a large iatrogenic rectal perforation due to endoscopic mucosal resection (EMR) and its subsequent conservative treatment.

A 65-year-old woman with a flat 30-mmwide rectal adenoma underwent EMR after injection of $0.4 \%$ sodium hyaluronate ( Fig. 1 a).

The lesion was completely removed; however, a 25-mm-wide perforation was noted on the posterior wall at $10 \mathrm{~cm}$ from the anal verge. The perforation was too large to be closed by endoclipping, so the marginal mucosa of the perforation was circumferentially attached to the presacral tissue adjacent to the rectum using endoclips ( Fig.1 b). Computed tomography (CT) revealed free air in the presacral space, but no pneumoperitoneum (๑ Fig. 2a). 
The patient was asymptomatic and her general status was stable. Therefore, conservative treatment was instituted, with intravenous antibiotic injections and discontinuance of oral nutrition. On the next day, the patient's white blood cell count and C-reactive protein level were normal; the amount of free air observed on CT had not increased ( Fig. 2 b). Proctoscopy revealed closure of the perforation 10 days later ( Fig. 1c), and the patient was discharged on day 16 . At 2 years after EMR she has had no further complication. The resected specimen was $38 \mathrm{~mm}$ wide, and the pathological diagnosis was tubulovillous adenoma (diameter $30 \mathrm{~mm}$; - Fig. 3).

Endoscopy_UCTN_Code_TTT_1AQ_2AJ

Competing interests: None
H. Sashiyama, K. I. Fu, Y. Hamahata,

O. Tsutsumi, T. Hoshino, Y. Tsujinaka

Department of Coloproctology, Tokatsu

Tsujinaka Hospital, Abiko, Chiba, Japan

\section{References}

1 Taku K, Sano Y, Fu KI et al. Iatrogenic perforation associated with therapeutic colonoscopy: a multicenter study in Japan. J Gastroenterol Hepatol 2007; 22: 1409-1414

2 Chu Q Petros JG. Extraperitoneal rectal perforation due to retroflexion fiberoptic proctoscopy. Am Surg 1999; 65: 81 - 85

3 Thomson SR, Fraser M, Stupp C et al. Iatrogenic and accidental colon injuries - what to do? Dis Colon Rectum 1994; 37: 496-502

4 Nivatvongs $S$. Complication in colonoscopic polypectomy. Dis Colon Rectum 1986; 29 : $825-830$

5 Taku K, Sano Y, Fu KI et al. Iatrogenic perforation at therapeutic colonoscopy: should the endoscopist attempt closure using endoclips or transfer immediately to surgery? Endoscopy 2006; 38: 428
Bibliography

Dol 10.1055/s-0030-1255767

Endoscopy 2011; 43: E81 - E82

(c) Georg Thieme Verlag KG Stuttgart · New York . ISSN 0013-726X

\section{Corresponding author} H. Sashiyama, MD

Department of Coloproctological Surgery Tsujinaka Hospital Kashiwanoha

178-2 Wakashiba, Kashiwa

Chiba

Japan 277-0871

Fax: +81-4-71873737

sasiyama@hotmail.com 